\title{
Characteristics and Mechanicals Potentials of Wood Adhesives Manufactured with Grasses' Lignins
}

\author{
Lionel Tapsia Karga ${ }^{1,2}$, Danwe Raidandi',3, Noel Konai', Antonio Pizzi ${ }^{4}$, Lucien Meva'a' \\ ${ }^{1}$ Laboratory of Mechanics and Civil Engineering, National Advanced School of Engineering, University of Yaoundé 1, \\ Yaoundé, Cameroon \\ ${ }^{2}$ Department of Mechanical Engineering Petroleum and Gas, Faculty of Mines and Petroleum Industries, \\ University of Maroua, Kaélé, Cameroon \\ ${ }^{3}$ Departement of Mechanical Engineering and Materials, National Advanced School of Engineering, University of Maroua, \\ Maroua, Cameroon \\ ${ }^{4}$ ENSTIB-LERMAB, University of Lorraine, Epinal, France \\ Email: *kalionel@yahoo.fr
}

How to cite this paper: Karga, L.T., Raidandi, D., Konai, N., Pizzi, A. and Meva'a, L. (2019) Characteristics and Mechanicals Potentials of Wood Adhesives Manufactured with Grasses' Lignins. Journal of Materials Science and Chemical Engineering, 7, 35-47.

https://doi.org/10.4236/msce.2019.71004

Received: November 24, 2018

Accepted: January 25, 2019

Published: January 28, 2019

Copyright (c) 2019 by author(s) and Scientific Research Publishing Inc. This work is licensed under the Creative Commons Attribution International License (CC BY 4.0)

http://creativecommons.org/licenses/by/4.0/

\begin{abstract}
In order to manufacture environmentally friendly particle boards and enhance local resources, the lignins of Sorghum bicolor and Andropogon gayanus characterized using RMN ${ }^{13} \mathrm{C}$ and MALDI TOF have the same structures. They contents Guaiacyl (G), Syringyl (S), p-hydroxyphenylpropane $(\mathrm{H})$ and functional groups of phenols, flavonoids and secondary alcohols. The total phenol content determinated using Folin-Ciocalteu reagent is respectively 20.97 and $15.42 \mathrm{mg}$ eqgallic acid/g of extract. The power of their adhesives is different. The Internal Bond (IB) of particleboards manufactured with these adhesives are respectively $0.37 \mathrm{MPa}$ and $0.41 \mathrm{MPa}$. These lignins can be used as antioxydants.
\end{abstract}

\section{Keywords}

Lignins, Sorghum bicolor and Andropogon gayanus, Structures, Adhesives, Internal Bond, Antioxydants

\section{Introduction}

Plants constituents such as lignin, tannin, hemicellulose and others are interesting. Many searchers in various fields such as in the paper industry, pharmaceutical industry, bakeries, wood adhesives etc. [1]. The most quantities of lignins are used in the paper industry. Their demand is increasing today due to their uses in 
the manufacturing of renewable polymers as one of the best solutions to environmental pollution [2]. In order to add value to lignins, many species have been characterized in the last decades. While Ghaffar has analyzed and characterized the structure of straw lignin [3], Gellerstedt et al. (2008) [4] have characterized the structures and properties of lignins for composites from renewables resources. Nadji et al. have done in 2009 a comparative study of lignins isolated from Alfa grass (Stipa tenacissima L.) [5]. Lignin is composed by three p-hydroxycinnamyl alcohol precursors: p-coumaryl, coniferyl and sinapyl alcohols [6]. Lignin has a highly complex 3D randomized structure linked to hemicelluloses. It functions as a biological barrier and as a binder holding together hemicelluloses and cellulose. Profiting from its unique structure in nature, lignin has significant potential to acquire added value to produce phenolic chemicals. Thus, lignin capability to produce high added value phenolic compounds has recently attracted a great deal of interest by the scientific community [6]. Many lignins have been used in the development of adhesives, such as Miscanthus lignin [7], wheat straw [8] and sugar maple [9]. A number of lignins have been characterized using several techniques, including Fourier trans-form infrared spectroscopy (FT IR), size exclusion chromatography (SEC), Matrix Assisted Laser Desorption Ionization Time of Flight Mass Spectrometry (MALDI-TOF MS) and Nuclear Magnetic Resonance spectroscopy (NMR) [3].

This idea of upgrading local materials and replacing all synthetic resins in the wood industry with biodegradable resins made from renewable resources such as wood, grasses and bone is of economic importance particularly for African countries in development. It can be of great interest in reducing the effect of climate change in some part of this continent (the sub-Saharan Africa).

Sorghum bicolor is a cereal and forage grass which belongs to the Poaceae family and the Andropogoneae tribe. It is the world's fifth largest cereal, after maize, rice, wheat and barley [10]. It is a basic cereal plant most cultivated in sub-Saharan Africa and particularly in the Far North of Cameroon. Rich in iron, calcium and phosphorus, sorghum would be an ideal food for diabetics. In Afri$\mathrm{ca}$, It is used as food and for treatment of various diseases such as gastrointestinal pathologies, to treat bone decalcification and to prevent gallstones. In sub-Saharan Africa, and particularly in the northern part of Cameroon, Andropogon is used as a building material. These more or less leaf-free stems are woven into mats, called "secco", and used in the construction of huts, fences, hangars, and roofs or sold in peri-urban markets while Sorghum bicolor stems are used in the construction of huts, Fences, sheds and manufacturing germ seed.

Despite the multiple benefits of Andropogon gayanus and Sorghum bicolor stems, these gramineae are not managed efficiently, they are waste often thrown into the wild, sometimes burned and used as firewood in households in the Northern Cameroon and they simply need to be upgraded. The Andropogon particularly is often a source of environmental hazards because it is often the source of the bush fires. Thus, the extraction of their lignins would constitute a 
great economic potential for these African countries because resins and biodegradable composite materials will be manufactured locally [11].

It is in this context that the present paper responds to this approach in investigating the applicability of the lignin of sorghum bicolor and Andropogon gayanus stem. Given the importance of sorghum bicolor and Andropogon gayanus species in Africa in general, and Cameroon in particular, and that of lignin in the wood and pharmaceutical industries, a sound knowledge of the chemical structure of sorghum bicolor and Andropogon gayanus using Matrix Assisted Laser Desorption Ionization Time of Flight Mass Spectrometry (MALDITOF MS) and Carbon-13 Nuclear Magnetic Resonance ( ${ }^{13} \mathrm{C}$ NMR) spectroscopy and the mechanical characteristics of particle board made from these lignins resins constitutes our interest center.

\section{Materials and Methods}

\subsection{Extraction}

$140 \mathrm{~g}$ of each sample (sorghum bicolor and Andropogon gayanus) stems crushed and $980 \mathrm{ml}$ of $\mathrm{NaOH}(0.7-1 \mathrm{M})$ were mixed in a reactor of 2 liters, and boiled at $170^{\circ} \mathrm{C}$ during 3 hours. After cooling the boiled content during 2 hours, it was sieved to obtained black liquor at $\mathrm{pH}=5.5$ adjusted using sulfuric acid. Then, the precipitate lignin was filtrated on the vacuum and watch with distillated water till neutral. The lignin obtained was stoved in an oven at $45^{\circ} \mathrm{C}$ during 48 hours [12].

\subsection{Total Phenolic Content}

$0.0125 \mathrm{~g}$ extract of each sample above was diluted in $25 \mathrm{ml}$ of methanol to obtain a final absorbance in the range $[0,0.5]$. Portion of $2.5 \mathrm{~mL}$ of Folin-Ciocalteu reagent that has been pre-diluted ten times in methanol, then $2 \mathrm{~mL}$ of an aqueous sodium carbonate solution $(75 \mathrm{~g} / \mathrm{L})$ were added to $0.5 \mathrm{~mL}$ of the methanolic solution of the extract. Sodium carbonate is added $30 \mathrm{~s}$ to $8 \mathrm{~min}$ after the Folin-Ciocalteu reagent. The resulting mixture was maintained during 5 min in a water bath at $50^{\circ} \mathrm{C}$ and then dipped in a cold water bath. The mixture was centrifuged and the absorbance of the supernatant liquid was determined at 760 $\mathrm{nm}$ with a Perkin-Elmer UV Lambda Spectrophotometer. The total phenolic content was calculated as gallic acid equivalent from the calibration curve of a gallic acid standard solution ( $0-25 \mathrm{mg} / \mathrm{L})$ and expressed as milligrams of gallic acid equivalent/g of extract. All tests were repeated three times [13].

\subsection{Matrix Assisted Laser Desorption Ionization Time of Light Mass Spectrometry (MALDI-TOF MS)}

$5 \mathrm{mg}$ of each lignin extract were dissolved in $1 \mathrm{~mL}$ of acetone and the obtained solution was mixed with another one composed of acetone $(10 \mathrm{mg} / \mathrm{mL}$ acetone) and 2,5-dihydroxybenzoic acid as matrix. Then, add the sodium chloride $(\mathrm{NaCl})$ to the matrix $(10 \mathrm{mg} / \mathrm{mL}$ in distilled water) to enhance the ion formation. The 
resulting solutions were evaporated on the MALDI target before placing into the spectrometer. The KRATOS compact MALDI AXIMA PERFORMANCE MALDI TOF 2 instrument was used to record the spectra. The irradiation source was a pulsed nitrogen laser (wave-length: $337 \mathrm{~nm}$, laser pulse length $3 \mathrm{~ns}$, and target type: ground steel).

\subsection{Solid State Carbon-13 Nuclear Magnetic Resonance ( ${ }^{13} \mathrm{C}$ NMR)}

A Bruker MSL spectrometer (Bruker Biospin, Wissembourg, France) was used to analyze the Carbon-13 Nuclear Magnetic Resonance (13C NMR). The spectra were acquired with $5 \mathrm{~s}$ recycle delays, a $90^{\circ}$ pulse of $4.2 \mu \mathrm{s}$ and a contact time of $1 \mathrm{~ms}$. The number of transients used was 3000 [14].

\subsection{Adhesives Development and Particleboards Manufacture and Testing}

A water solution containing $35 \%$ lignin extract was mixed with 5\% paraformaldehyde powder and $\mathrm{pH}$ was adjusted to 10 adding sodium hydroxide solution $(\mathrm{NaOH})$. All components weight are on solids lignin. The components of each formulation was mixed in a beaker at $25^{\circ} \mathrm{C}$ temperature, process was stopped when viscosity reached $750 \mathrm{mPas}$ using Brookfield viscometer RV. Spindle $\mathrm{Nr}$, 27 at $25^{\circ} \mathrm{C}$. Two formulations of adhesives with those lignins extract where developed. These adhesives were used to manufacture particle boards.

Two particleboards of $350 \times 300 \times 14 \mathrm{~mm}^{3}$ dimension were prepared using particles of Sorghum bicolor and Andropogon gayanus (moisture content $=2 \%$ ) at $28 \mathrm{~kg} / \mathrm{cm}^{2}$ maximum pressure and $190^{\circ} \mathrm{C}-200^{\circ} \mathrm{C}$ press temperature during 7.5 min. The total adhesive resin solids load on dry wood was $10 \% \mathrm{w} / \mathrm{w}$ of the total mix of different lignin. The particleboards were tested for dry internal bond (IB) strength in accordance with the standard EN312.

\section{Results and Discussion}

\subsection{Total Phenol Content}

The total phenolic content of Sorghum bicolor lignin and Andropogon gayanus in the solvent measured by the Folin-Ciocalteu method are respectively 20.97 and $15.42 \mathrm{mg}$ eqgallic acid/g of extract. The possibility to uses this lignin as adhesive is showed by the existence of phenol in this extract [15].

\subsection{Matrix Assisted Laser Desorption Ionization Time of Light Mass Spectrometry (MALDI-TOF MS)}

The examination of the MALDI TOF spectra of Sorghum bicolor and Andropogon gayanus lignin in Figure 1 and Figure 2 in the range 200 to $699 \mathrm{Da}$ and 100 to $4000 \mathrm{Da}$ respectively, shows the 3 most common monomers participating in the formation of the lignin oligomers: $G$ (guaiacyl), $S$ (syringyl) and $H$ (p-hydroxyphenylpropane). The MALDI-TOF spectrum between 20 and $200 \mathrm{Da}$ was recorded but is not reported here. The molecular weight corresponding to 


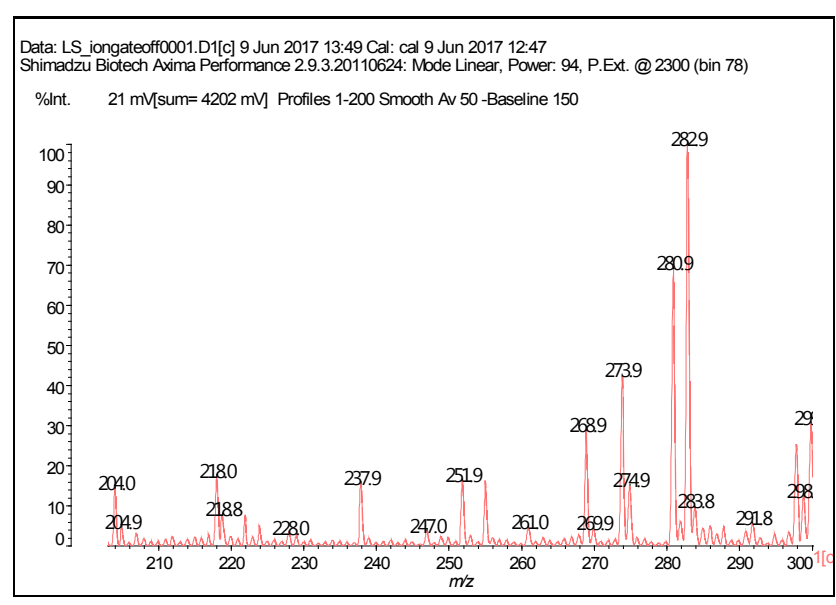

(a)

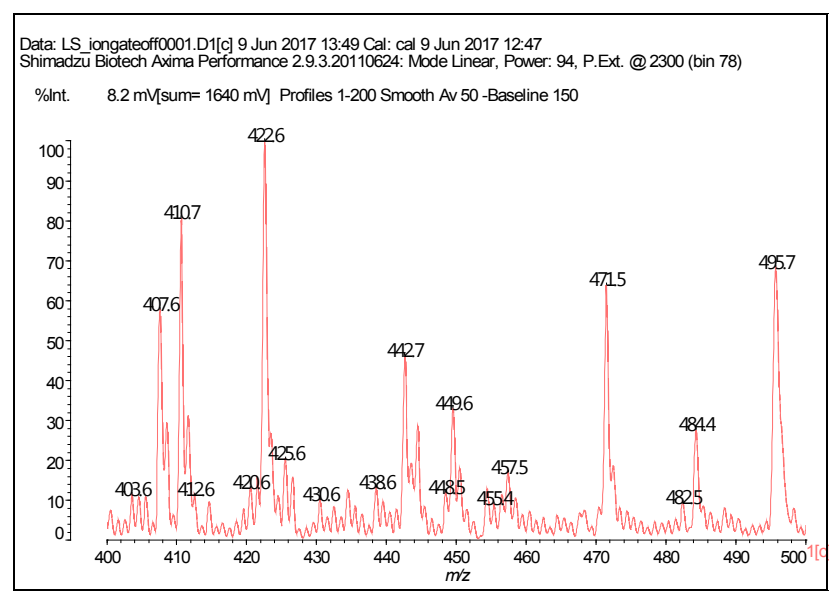

(c)

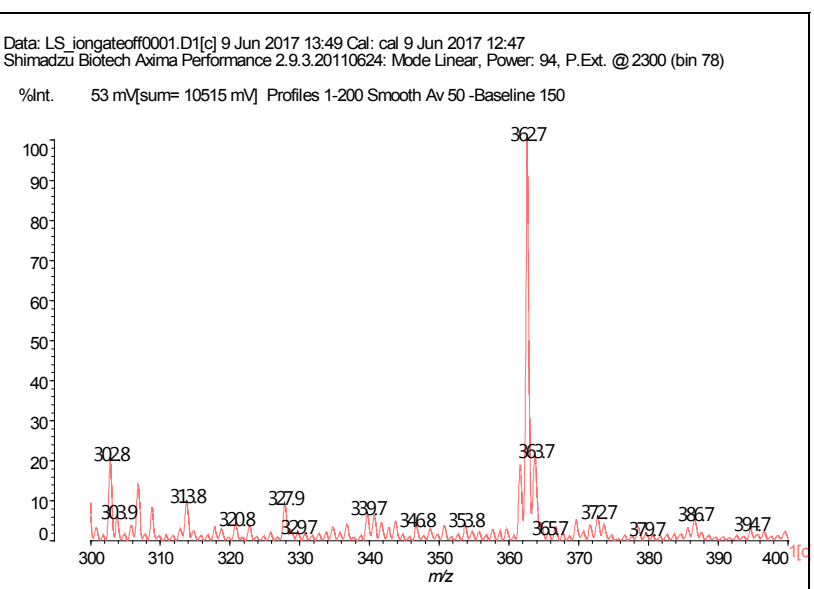

(b)

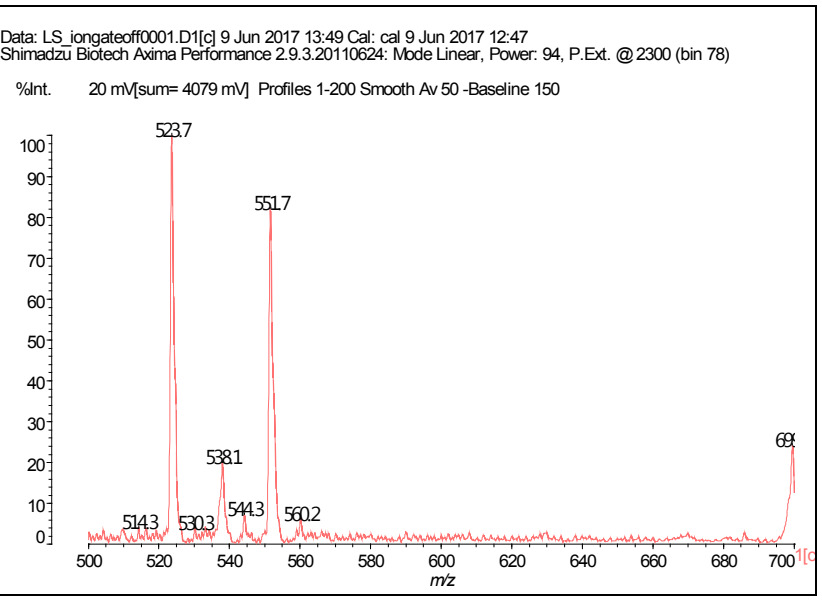

(d)

Figure 1. (a) MALDI-TOF spectrum of Sorghum bicolor lignin in the a 200 - 300 Da range; (b) MALDI-TOF spectrum of Sorghum bicolor lignin in the a 300 - 400 Da range; (c) MALDI-TOF spectrum of Sorghum bicolor lignin in the a 400 - 500 Da range; (d) MALDI-TOF spectrum of Sorghum bicolor lignin in the a $500-700 \mathrm{Da}$ range.

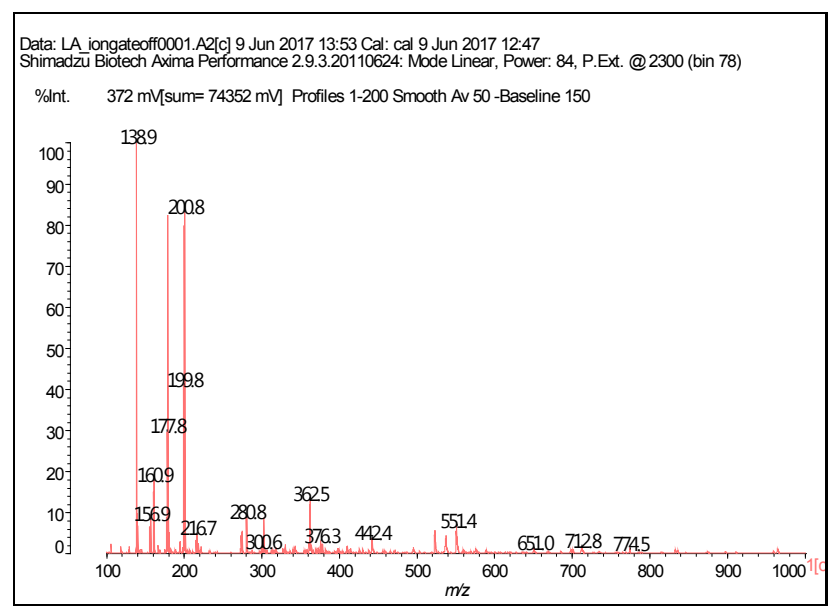

(a)

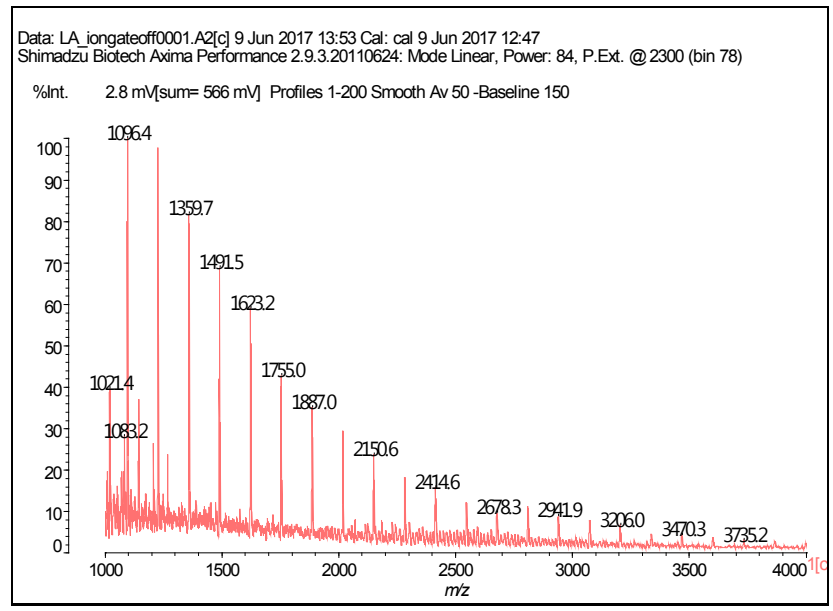

(b)

Figure 2. (a) MALDI-TOF spectrum of Andropogon gayanus lignin in the a 100 - 1000 Da range; (b) MALDI-TOF spectrum of Andropogon gayanus lignin in the a 1000 - 4000 Da range. 
these monomers are: 94; $139 \mathrm{Da}$ (for $\mathrm{H}$ ); 151; 182 and $197 \mathrm{Da}$ (for G) and 210 (for S) Da (Table 1 and Table 2) [16]. The linkages between them are indicated by the "classical" nomenclature such as $\beta-\mathrm{O}-4, \alpha-\mathrm{O}-4, \beta-\beta, \beta-5,5-5$ ' [13]. The peak $430 \mathrm{Da}$ correspond to the G- $\beta$-O4-S or G- $\alpha-\mathrm{O} 4-\mathrm{S}$ structures. The values in $\mathrm{Da}$ of the structures corresponding to these peaks must be subtracted of $23 \mathrm{Da}$ to obtain the value of their molecular weight from the peaks of the MALDI spectrum due to the $\mathrm{NaCl}$ matrix enhancer used. During the formation of oligomers, the loss of either a hydrogen atom or the protonated form [17] and the loss of a hydroxyl group [18] of the monomer units must be taken into account if they are not the terminal units of the oligomers. The losed of the water molecules must be taken into consideration, since water molecule will be eliminated ( 1 water molecule for every 2 monomers) from the oligomer during the condensation. The spectra of each lignin grasses revealed the presence Protonated or multiprotonated (with $\mathrm{Na}^{+}$) oligomers and there are some oligomers which have lost or acquired an $\mathrm{OH}$ group [17] (Table 2 and Table 3 ). There are some signals in the range of $482-700 \mathrm{Da}$ confirming the presence of trimers $\mathrm{S}-\beta \mathrm{O} 4-\mathrm{H}-\beta 5-\mathrm{G}$, G- $\beta \mathrm{O} 4-\mathrm{G}-\beta 5-\mathrm{G}$ and $\mathrm{S}-\beta \mathrm{O} 4-\mathrm{S}-\beta \beta-\mathrm{S}$. Regarding the molarsmasses of these twolignins, namely $4000 \mathrm{Da}$ forandropogonand $700 \mathrm{Da}$ for Sorghum bicolor, we deducethat the degree of polymerization of andropogonlignin is greaterthanthat of Sorghum bicolor lignin.

\subsection{Solid State Carbon-13 Nuclear Magnetic Resonance ( ${ }^{13} \mathrm{C}$ NMR)}

Further information on the chemical structure of lignin extracts of Andropogon gayanus (LA) and lignin sorghum bicolor (LS) was obtained by ${ }^{13} \mathrm{C}$ NMR. The peaks of the spectra in Figure 3 and Figure 4 show the shifts of the components or functional groups of the monomers present in the lignin extract of Andropogon gayanus and bicolor sorghum. Each peak is associated with either a functional group or a monomer present in these lignin extracts. The attributions of the different peaks of these lignins extracts are listed in Table 4 according to the literature [19]. The Analysis of the ${ }^{13} \mathrm{C}$ NMR spectra in Figure 3 and Figure 4 shows that peaks $152.75 ; 148.23133 .63 ; 102.59 \mathrm{ppm}$ for LS and $153.37 ; 148.03$; $134.04 ; 102.38 \mathrm{ppm}$ for LA indicate the presence of syringyl units (S) while the signals at $148.23 ; 115.54 \mathrm{ppm}$ indicate the presence of a guaiacyl unit $(\mathrm{G})$. The peaks $115.54 \mathrm{ppm}$ for LS and $114.92 \mathrm{ppm}$ for LA can also be attributed to C5 in p-hydroxyphenyl $(\mathrm{H})$ or in guaiacyl unit $(\mathrm{G})$ [20]. The peak 128.08 is assigned to C2/C6 in p-hydroxyphenyl $(\mathrm{H})$. These peaks confirm that the lignin extract can be an herbaceous lignin (HGS) as indicated by MALDI TOF analysis. In addition, the ${ }^{13} \mathrm{C}$ NMR spectra of lignin extracts of Andropogon gayanus and bicolor sorghum are similar to those of herbaceous crops [20]. The very high intensity of the peak at $73.60 \mathrm{ppm}$ for LS is associated with the $\mathrm{Ca}$ in $\beta-\mathrm{O}-4$ shows that the $\beta$-O-4 bond is the most abundant in the lignin extract of Sorghum bicolor. Signals at $82.23 ; 82.65 \mathrm{ppm}$ are associated with $\mathrm{C}-\alpha$ and $\mathrm{C}-\beta$ in $\beta-\mathrm{O}-4 / \alpha-\mathrm{O}-4$ and $\mathrm{C}-\alpha$ in $\beta 5$ and $\beta \beta$. Peaks 63.73 and $63.94 \mathrm{ppm}$ are attributed to $\mathrm{C}-\Upsilon$ in $\beta-5$ side chain carbons. The peaks at 55.92 and 55.71 ppm correspond to the methoxyl 
Table 1. Monomers and oligomers present in Sorghum bicolor lignin extract.

\begin{tabular}{|c|c|c|c|c|c|}
\hline \multicolumn{2}{|c|}{ structure } & $\begin{array}{l}\text { Calculated } \\
\text { M.W }\end{array}$ & $\begin{array}{l}\text { Calculated } \\
\mathrm{M} . \mathrm{W}+\mathrm{Na}\end{array}$ & $\begin{array}{c}\text { Experimental } \\
\text { peak }\end{array}$ & $\begin{array}{c}\text { Peak relative } \\
\text { proportion (\%) }\end{array}$ \\
\hline G $1 \mathrm{H}$ & monomer & 181 & 204 & 204 & 15 \\
\hline $\mathrm{G}-2 \mathrm{H}$ & monomer & 195 & 218 & 218 & 20 \\
\hline S-5H & monomer & 205 & 228 & 228 & 5 \\
\hline $\mathrm{S}+4 \mathrm{H}$ & monomer & 214 & 237 & 237 & 18 \\
\hline $\mathrm{S}+6 \mathrm{H}$ & monomer & 224 & 247 & 247 & 5 \\
\hline $\mathrm{H}-\mathrm{G}-\mathrm{OH}$ & dimer & 228 & 251 & 251 & 15 \\
\hline H-G-7H & dimer & 238 & 261 & 261 & 8 \\
\hline $\mathrm{H}-\mathrm{G}$ & dimer & 245 & 268 & 268 & 28 \\
\hline$H-G+1 H$ & dimer & 246 & 269 & 269 & 5 \\
\hline$H-G+5 H$ & dimer & 250 & 273 & 273 & 37 \\
\hline S-S- $\mathrm{CH}_{3}$ & dimer & 251 & 274 & 274 & 15 \\
\hline G-H-2OH & dimer & 257 & 280 & 280 & 65 \\
\hline S-S-7H & dimer & 259 & 282 & 282 & 97 \\
\hline $\mathrm{G}-\mathrm{H}+6 \mathrm{H}$ & dimer & 260 & 283 & 283 & 10 \\
\hline $\mathrm{S}-\mathrm{S}+2 \mathrm{H}$ & dimer & 268 & 291 & 291 & 5 \\
\hline $\mathrm{S}-\mathrm{S}+3 \mathrm{H}$ & dimer & 279 & 302 & 302 & 21 \\
\hline $\mathrm{G}-\mathrm{G}+4 \mathrm{H}$ & dimer & 280 & 303 & 303 & 15 \\
\hline G-H & dimer & 290 & 313 & 313 & 10 \\
\hline $\mathrm{G}-\mathrm{H}+7 \mathrm{H}$ & dimer & 297 & 320 & 320 & 5 \\
\hline $\begin{array}{l}\text { H-S } \\
\text { G-G }\end{array}$ & dimer & 304 & 327 & 327 & 10 \\
\hline $\begin{array}{c}\mathrm{H}-\mathrm{S} \\
\mathrm{G}-\mathrm{G}+2 \mathrm{H}\end{array}$ & dimer & 306 & 329 & 329 & 5 \\
\hline $\begin{array}{c}\mathrm{H}-\mathrm{S} \\
\text { G-G-CO }\end{array}$ & dimer & 316 & 339 & 339 & 9 \\
\hline $\mathrm{S}-\mathrm{H}-\mathrm{CH}_{2}$ & dimer & 323 & 346 & 346 & 5 \\
\hline $\mathrm{G}-\mathrm{G}+2 \mathrm{OH}$ & dimer & 330 & 353 & 353 & 5 \\
\hline $\mathrm{H}-\mathrm{G}+3 \mathrm{H}$ & dimer & 339 & 362 & 362 & 100 \\
\hline H-G-2H & dimer & 340 & 363 & 363 & 3 \\
\hline $\begin{array}{c}\text { G-H- } \mathrm{H}_{2} \mathrm{O} \\
\text { S-H }\end{array}$ & dimer & 342 & 365 & 365 & 3 \\
\hline $\begin{array}{c}\mathrm{H}-\mathrm{S} \\
\mathrm{G}-\mathrm{H}-\mathrm{CH}_{3}\end{array}$ & dimer & 345 & 368 & 368 & 12 \\
\hline $\mathrm{S}-\mathrm{H}$ & dimer & 349 & 372 & 372 & 5 \\
\hline H-G-1H & dimer & 356 & 379 & 379 & 4 \\
\hline $\begin{array}{c}\text { G-G } \\
\mathrm{S}-\mathrm{H}+3 \mathrm{H}\end{array}$ & dimer & 363 & 386 & 386 & 5 \\
\hline G-G-2H & dimer & 371 & 394 & 394 & 4 \\
\hline G-G-2H & dimer & 380 & 403 & 403 & 12 \\
\hline $\mathrm{G}-\mathrm{G}-\mathrm{H}_{2} \mathrm{O}$ & dimer & 384 & 407 & 407 & 68 \\
\hline
\end{tabular}




\begin{tabular}{|c|c|c|c|c|c|}
\hline Continued & & & & & \\
\hline $\mathrm{G}-\mathrm{G}+2 \mathrm{H}$ & dimer & 387 & 410 & 410 & 82 \\
\hline $\mathrm{G}-\mathrm{S}-\mathrm{H}_{2} \mathrm{O}$ & dimer & 389 & 412 & 412 & 15 \\
\hline G-G-2H & dimer & 397 & 420 & 420 & 16 \\
\hline G-G-4H & dimer & 399 & 422 & 422 & 100 \\
\hline G-S-5H & dimer & 402 & 425 & 425 & 22 \\
\hline G-S & dimer & 407 & 430 & 430 & 12 \\
\hline $\mathrm{G}-\mathrm{S}+8 \mathrm{H}$ & dimer & 415 & 438 & 438 & 15 \\
\hline $\mathrm{S}-\mathrm{S}-\mathrm{OH}$ & dimer & 419 & 442 & 442 & 42 \\
\hline $\mathrm{G}-\mathrm{S}+\mathrm{H}_{2} \mathrm{O}$ & dimer & 425 & 448 & 448 & 13 \\
\hline S-S- $11 \mathrm{H}$ & dimer & 426 & 449 & 449 & 32 \\
\hline S-S-5H & dimer & 432 & 455 & 455 & 12 \\
\hline S-S-3H & dimer & 434 & 457 & 457 & 18 \\
\hline $\mathrm{S}-\mathrm{S}+\mathrm{H}_{2} \mathrm{O}$ & dimer & 448 & 471 & 471 & 62 \\
\hline S-H-G-4H & trimer & 459 & 482 & 482 & 10 \\
\hline S-H-G-2H & trimer & 461 & 484 & 484 & 28 \\
\hline H-H-G-3H & trimer & 472 & 495 & 495 & 65 \\
\hline S-H-G & trimer & 491 & 514 & 514 & 5 \\
\hline S-H-G & trimer & 500 & 523 & 523 & 100 \\
\hline $\mathrm{S}-\mathrm{H}-\mathrm{G}+7 \mathrm{H}$ & trimer & 507 & 530 & 530 & 5 \\
\hline $\mathrm{S}-\mathrm{S}-\mathrm{H}+2 \mathrm{H}$ & trimer & 515 & 538 & 538 & 20 \\
\hline S-S-H-2H & trimer & 521 & 544 & 544 & 7 \\
\hline S-S-H-1H & trimer & 528 & 551 & 551 & 82 \\
\hline G-G-G-3H & trimer & 537 & 560 & 560 & 8 \\
\hline $\mathrm{S}-\mathrm{S}-\mathrm{S}+\mathrm{CH}_{3} \mathrm{O}$ & trimer & 676 & 699 & 699 & 5 \\
\hline
\end{tabular}

group $\mathrm{OCH}_{3}$ in the syringyl and guaiacyl units. The very high intensity of the signal at $75.04 \mathrm{ppm}$ corresponds to the aliphatic group $-\mathrm{CH}_{2} \mathrm{OH}$ of the side chain of the lignin unit. The signal associated with the $\alpha$ and $\beta$-methylene group on the n-propyl side chains appears at 31.25 and $30.42 \mathrm{ppm}$ [21]. Peaks 177.22 and $176.60 \mathrm{ppm}$ are attributed to the non-conjugated $\mathrm{CO}_{2} \mathrm{H}$ carboxyl group in this lignin [22]. All information from these ${ }^{13} \mathrm{C}$ NMR spectra confirms the presence of guaiacyl, syringyl units, a small amount of p-hydroxyphenyl units and phenols, as shown by the MALDI TOF. The presence of phenols and flavonoids in these lignins extracts show that they can be used as wood adhesives and can also be used as antioxidants.

\subsection{Adhesives Development and Particleboards Manufacture and Testing}

Particleboards manufactured with the two formulations of lignin resins of Andropogon (LPA4055) and Sorghum (LPS4055) had good IB strength. Result 
Table 2. Monomers and oligomers present in Andropogon gayanus lignin extract.

\begin{tabular}{|c|c|c|c|c|c|}
\hline structure & & $\begin{array}{l}\text { Calculated } \\
\text { M.W }\end{array}$ & $\begin{array}{l}\text { Calculated } \\
\mathrm{M} . \mathrm{W}+\mathrm{Na}\end{array}$ & $\begin{array}{c}\text { Experimental } \\
\text { peak }\end{array}$ & $\begin{array}{c}\text { Peak relative } \\
\text { proportion (\%) }\end{array}$ \\
\hline $\mathrm{G}-5 \mathrm{H}$ & Monomer & 177 & 200 & 200 & 85 \\
\hline $\mathrm{G}-4 \mathrm{H}$ & Monomer & 193 & 216 & 216 & 8 \\
\hline $\mathrm{H}-\mathrm{G}+12 \mathrm{H}$ & dimer & 257 & 280 & 280 & 12 \\
\hline $\mathrm{G}-\mathrm{H}+1 \mathrm{H}$ & dimer & 277 & 300 & 300 & 5 \\
\hline $\mathrm{S}-\mathrm{H}-10 \mathrm{H}$ & dimer & 339 & 362 & 362 & 18 \\
\hline $\mathrm{S}-\mathrm{H}+4 \mathrm{H}$ & dimer & 353 & 376 & 376 & 5 \\
\hline S-S-OH & dimer & 419 & 442 & 442 & 5 \\
\hline S-S-H-1H & trimer & 528 & 551 & 551 & 10 \\
\hline S-S-S-2H & trimer & 628 & 651 & 651 & 3 \\
\hline $\mathrm{H}-\mathrm{G}-\mathrm{H}-\mathrm{G}+11 \mathrm{H}$ & tetramer & 689 & 712 & 712 & 3 \\
\hline G-G-G-S + 1H & tetramer & 751 & 774 & 774 & 65 \\
\hline S-S-S-S-S-S & hexamer & 998 & 1021 & 1021 & 45 \\
\hline S-H-S-H-S-H-1H & hexamer & 1060 & 1083 & 1083 & 28 \\
\hline S-H-S-H-S-H-4H & hexamer & 1073 & 1096 & 1096 & 100 \\
\hline S-H-S-H-S-H-S-H- $4 \mathrm{H}$ & octamer & 1336 & 1359 & 1359 & 82 \\
\hline S-S-S-S-S-S-S-S-2H & heptamer & 1468 & 1491 & 1491 & 70 \\
\hline S-H-S-H-S-H-S-H-S-H & decamer & 1600 & 1623 & 1623 & 60 \\
\hline G-S-G-S-G-S-G-S - $\mathrm{CH}_{3}-\mathrm{OH}$ & octamer & 1732 & 1755 & 1755 & 42 \\
\hline G-G-G-G-G-G-G-G-G-G + $\mathrm{H}_{2} \mathrm{O}$ & decamer & 1864 & 1887 & 1887 & 35 \\
\hline H-S-H-S-H-S-H-S-H-S-H-S-H-S-1H & pentadecamer & 2127 & 2150 & 2150 & 22 \\
\hline H-G-H-G-H-G-H-G-H-G-H-G-H-G + $\mathrm{H}_{2} \mathrm{O}$ & tetradecamer & 2391 & 2414 & 2414 & 18 \\
\hline G-G-G-G-G-G-G-G-G-G-G-G-G-G-G-G-G-G & octadecamer & 2655 & 2678 & 2678 & 10 \\
\hline S-S-S-S-S-S-S-S-S-S-S-S-S-S $+\mathrm{CH}_{3}$ & tetradecamer & 2918 & 2941 & 2941 & 10 \\
\hline S-H-S-H-S-H-S-H-S-H-S-H-S-H-S-H-S-H + 6H & octadecamer & 3183 & 3206 & 3206 & 8 \\
\hline G-S-G-S-G-S-G-S-G-S-G-S-G-S-G-S-OH & hexadecamer & 3447 & 3470 & 3470 & 3 \\
\hline G-S-G-S-G-S-G-S-G-S-G-S-G-S-G-S-G-S + Na ${ }^{+}$ & octadecamer & 3712 & 3735 & 3735 & 5 \\
\hline
\end{tabular}

satisfied the dry IB strength requirement of the standard NF EN 312-2 (1996). Dry IB strength of particle boards manufactured with particles of Andropogon gayanus and the LPA4055 formulation was $0.37 \mathrm{MPa}$ (Figure 5) and those manufactured particles of Sorghum bicolor and the LPS4055 formulation was 0.41 MPa (Figure 6). These two IB values are higher the standard Norm NF EN 312-2 (1996) $(0.37>035 \mathrm{MPa}$ and $0.41>0.35 \mathrm{MPa})$.

\section{Conclusion}

MALDI-TOF MS and $13^{\circ} \mathrm{C}$ NMR analysis were used for the characterization of lignin extracted from the stem of Sorghum bicolor and Andropogon gayanus. 


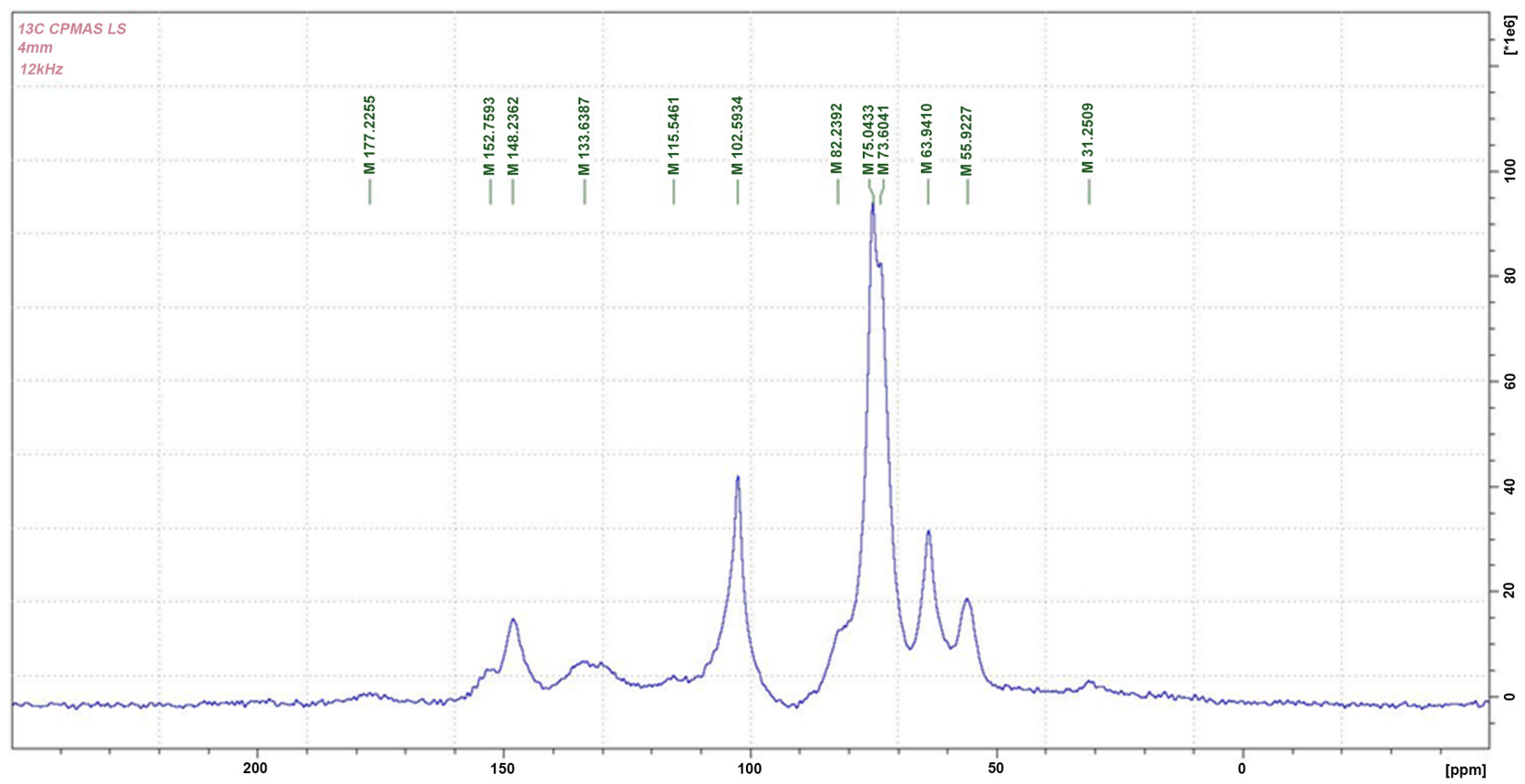

Figure $3 .{ }^{13} \mathrm{C}$ NMR Spectrum of Sorghum bicolor lignin extract (LS).

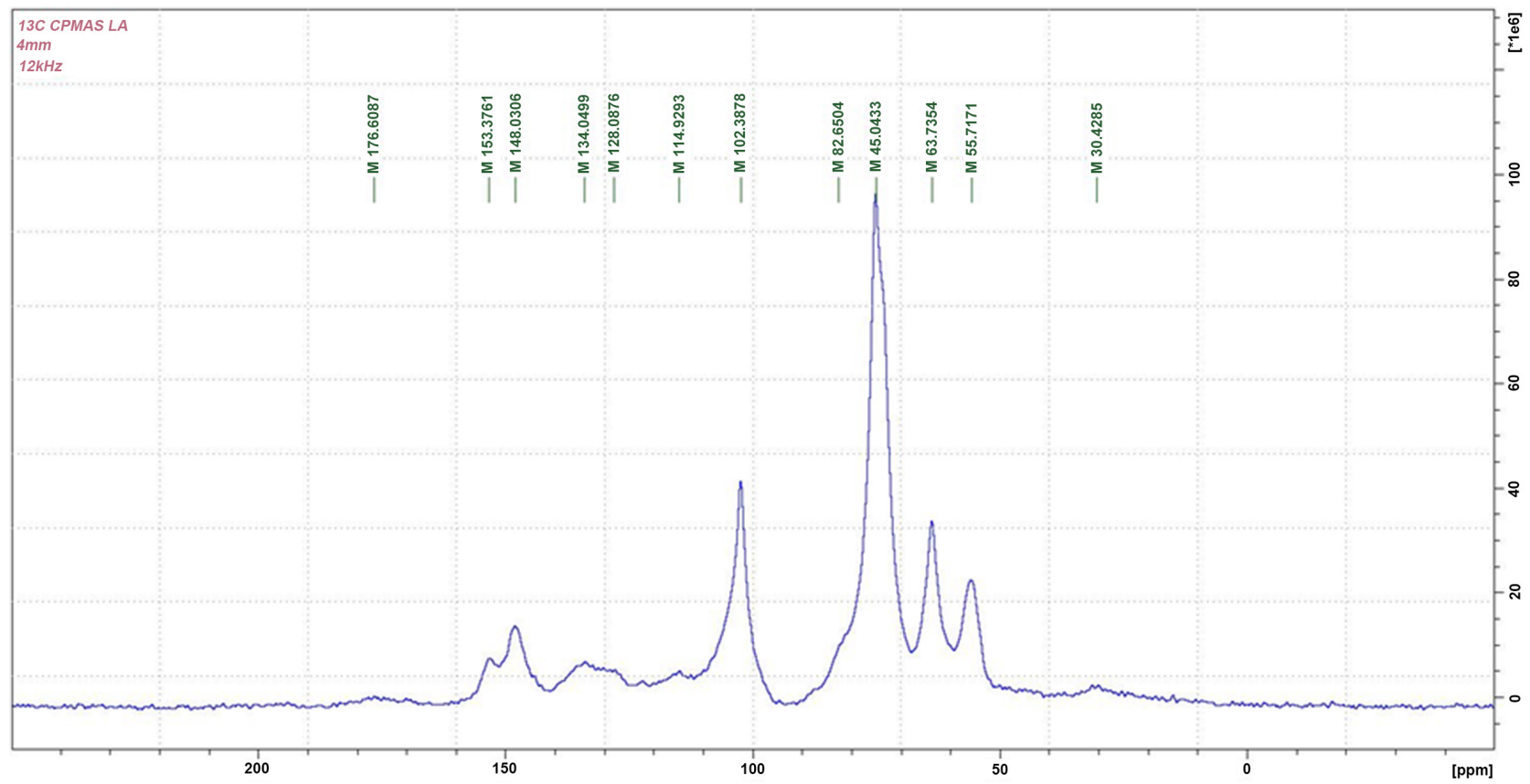

Figure $4 .{ }^{13} \mathrm{C}$ NMR Spectrum of Andropogon gayanus lignin extract (LA).

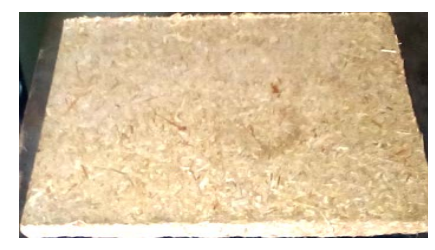

Figure 5. Particleboard of Andropogon gayanus. 


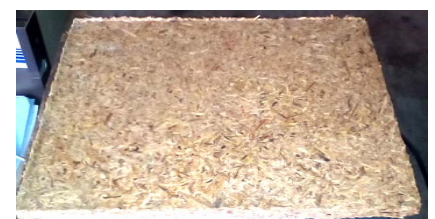

Figure 6. Particleboard of Sorghumbicolor.

Table 3. Carbon chemical shifts $(\delta$, ppm), intensity and assignment of the lignin preparation LS an LA in ${ }^{13} \mathrm{C}$ NMR spectrum.

\begin{tabular}{|c|c|c|c|c|c|}
\hline $\begin{array}{l}\text { Peak (ppm) } \\
\text { LS }\end{array}$ & $\begin{array}{c}\text { Intensity } \\
\%\end{array}$ & $\begin{array}{l}\text { Peak (ppm) } \\
\text { LA }\end{array}$ & $\begin{array}{c}\text { Intensity } \\
\%\end{array}$ & $\begin{array}{l}\text { Peak } \\
(\mathrm{ppm})\end{array}$ & Assignments \\
\hline 177.22 & 2 & 176.60 & 2 & $178.0-167.5$ & Unconjugated- $\mathrm{CO}_{2} \mathrm{H}$ \\
\hline 152.75 & 10 & 153.37 & 10 & $154-152$ & C3/C5 S etherified \\
\hline 148.23 & 15 & 148.03 & 15 & $148-147$ & $\begin{array}{c}\text { C4 G etherified, C3C5 S non } \\
\text { etherified }\end{array}$ \\
\hline \multirow[t]{2}{*}{133.63} & 5 & 134.04 & 5 & 134 & $\mathrm{C} 1 \mathrm{~S}$ or $\mathrm{C} 1$ in $\mathrm{G} \beta-\mathrm{O}-4$ \\
\hline & & 128.08 & 3 & 128 & $\mathrm{C} 2 / \mathrm{C} 6 \mathrm{H}$ \\
\hline 115.54 & 3 & 114.92 & 5 & 115 & C5 G \\
\hline 102.59 & 38 & 102.38 & 38 & $105-104$ & $\mathrm{C} 2 / \mathrm{C} 6 \mathrm{~S}$ \\
\hline 82.23 & 10 & 82.65 & 5 & $89-78$ & $\begin{array}{l}\mathrm{C} \beta \text { in } \beta-\mathrm{O}-4, \mathrm{C} \alpha \text { in } \beta 5 \text { and } \beta \beta \mathrm{C} \alpha \\
\text { and } \mathrm{C} \beta \text { in } \beta-\mathrm{O}-4 / \alpha-\mathrm{O}-4 \text { units }\end{array}$ \\
\hline 75.04 & 95 & 75.04 & 100 & & Aliphatic- $\mathrm{CH}_{2} \mathrm{OH}$ \\
\hline 73.60 & 80 & & & $73-71$ & $\mathrm{Ca}$ in $\beta-\mathrm{O}-4$ \\
\hline 63.94 & 30 & 63.73 & 30 & 64 & $\begin{array}{c}\mathrm{C} \gamma \text { in } \beta 5, \mathrm{C} \gamma \text { with } \mathrm{C} \alpha=\mathrm{O}, \mathrm{C} \gamma-\mathrm{O} \text { PC } \\
\text { ester }\end{array}$ \\
\hline 55.92 & 18 & 55.71 & 25 & 56 & $\mathrm{OCH}_{3}$ in $\mathrm{G}$ and $\mathrm{S}$ \\
\hline 31.25 & 2 & 30.42 & 2 & $31-29$ & $\alpha, \beta$ méthylène groups \\
\hline
\end{tabular}

$\mathrm{H}=$ Hydroxyphenyl; $\mathrm{S}=$ Syringyl $; \mathrm{G}=$ Guaiacyl; $\mathrm{LS}=$ Sorghum lignin $; \mathrm{LA}=$ Andropogon lignin

The analysis carried out had shown that these lignins consist of Guaiacyl $(G)$, Syringyl (S), p-hydroxyphenylpropane $(\mathrm{H})$ units and of phenolic, flavonoid and secondary alcohols functional groups. It is mainly composed of Guaiacyl (G) and Syringyl (S) units $\beta-\mathrm{O}-4$ linked. The presence of phenols and flavonoids in this lignin extract shows that it could be used as wood adhesives and as antioxidant. They are good for wood adhesive because IB for their particleboards is respectively 0.37 and $0.41 \mathrm{MPa}$. A study aimed at increasing the mechanical characteristics of these bio-based panels by combining for example tannin and lignin in the elaboration of bioadhesives since tannin and lignin form the essential of polyphenols present in the plant species.

\section{Acknowledgements}

The authors acknowledge Dr. FRANCISCO JOSE SANTIAGO MEDINA for his valuable support during laboratory experimentation carried out at the LERMAB, at the University of Lorraine (France), Pr NTEDE Head of the Laboratory of 
Chemistry of Higher National School of Engineering, University of Yaoundé 1, Dr. CHEMENI the Head of the Assistant Laboratory of Macromolecular Chemistry at the University of Yaoundé 1, Dr. Jean-Bosco Saha Tchinda, Mr. FokoStephan, Mr Agueda Fabrice and Mr. Njom Abel for their assistance.

\section{Conflicts of Interest}

The authors declare no conflicts of interest regarding the publication of this paper.

\section{References}

[1] Berrima, B. (2015) Etude structurale et chimique de la lignine d'Alfa et sa valorisation comme macromonomère et/ou précurseur du charbon actif. Génie des procédés. Université Grenoble Alpes, Français.

[2] Thakur, V., Raghavan, P. and Kessler, M.R. (2014) Progress in Green Polymer Composites from Lignin for Multifunctional Applications: A Review. ACS Sustain ChemEng, 2, 1072-1092. https://doi.org/10.1021/sc500087z

[3] Ghaffar, S.H. and Fan, M. (2013) Structural Analysis for Lignin Characteristics in Biomass Straw. Biomass Bioenergy, 57, 264-279.

https://doi.org/10.1016/j.biombioe.2013.07.015

[4] Gellerstedt, G. and Henriksson, G. (2008) Lignins: Major Sources Structures and Properties. In: Belgacem, M.N. and Gandini, A., Eds., Monomers Polymers and Composites from Renewables Resources, 201-224.

[5] Nadji, H., Diouf, P., Benaboura, A., Bedard, B., Riedl, T. and Stevanovic (2009) Comparative Study of Lignins Isolated from Alfa Grass (Stipa tenacissima L.). Bioresource Technology, 100, 3585-3592. https://doi.org/10.1016/j.biortech.2009.01.074

[6] Ragauskas, A.J., Beckham, G.T., Biddy, M., Richard, C., Fang, C., Mark, F., Davis, H. and Davison (2014) Lignin Valorization: Improving Lignin Processing in the Biorefinery. Science, 344, 709-719.

[7] El Hage, R., Brosse, N., Navarrete, P., et al. (2011) Extraction, Characterization and Utilization of Organosolv Miscanthus Lignin for the Conception of Environmentally Friendly Mixed Tannin/Lignin Wood Resins. Journal of Adhesion Science and Technology, 25, 1549-1560. https://doi.org/10.1163/016942410X524110

[8] Feng, X., Sun, J.X., Sun, R.C., et al. (2006) Comparative Study of Organosolvlignins from Wheat Straw. Industrial Crops and Products, 23, 180-193.

https://doi.org/10.1016/j.indcrop.2005.05.008

[9] Dongre, P., Driscoll, M., Amidon, T., et al. (2015) Lignin-Furfural Based Adhesives. Energies, 8, 7897-7914.

[10] Jacques, C., Jean-François, C., Alain, R. and Gilles, T. (2013) Le sorgho, Éditions Quæ, CTA, Presses agronomiques de Gembloux, 267 p.

[11] Noel, K., Raidandi, D., Pizzi, A., et al. (2016) Thermogravimetric Analysis of Anningre Tannin Resin. Maderas. Ciencia y Tecnología, 18, 245-252.

[12] Mousavioun, P. and Doherty, W. (2010) Chemical and Thermal Properties of Fractionated Bagasse Soda Lignin. Industrial Crops and Products, 31, 52-58.

[13] Huang, Z., Hashadi, K., Makino, R., Kawamura, F., Kuniyoshi, S., Ryuichiro, K. and Ohara, S. (2009) Evaluation of Biological Activities of Extracts from 22 African Tropical Wood Species. Journal of Wood Science, 55, 225-229. 
https://doi.org/10.1007/s10086-008-1024-y

[14] Navarrete, P., Pizzi, A., Pasch, H. and Delmotte, L. (2012) Study on Lignin-Glyoxal Reaction by MALDI-TOF and CP-MAS 13 C-NMR. Journal of Adhesion Science and Technology, 26, 1069-1082.

[15] Zhao, M.Z., Jing, J.L., Zhu, Y.C., Yang, X.M., Wang, X.F. and Wang, Z.C. (2016) Preparation and Performance of Lignin-Phenol-Formaldehyde Adhesives. International Journal of Adhesion \& Adhesives, 64, 163-167.

[16] Navarrete, P., Mansouri, H.R., Pizzi, A., et al. (2010) Wood Panel Adhesives from Low Molecular Mass Lignin and Tannin without Synthetic Resins. Journal of Adhesion Science and Technology, 24, 1597-1610. https://doi.org/10.1163/016942410X500972

[17] Konai, N., Pizzi, A., Raidandi, D., Lagel, M.C., L'Hostis, C., Saidou, C., Hamido, A., Abdalla, S., Bahabri, F. and Ganash A. (2015) Aningre (Aningeria spp.) Tannin Extract Characterization and Performance as an Adhesive Resin. Industrial Crops and Products, 77, 225-231. https://doi.org/10.1016/j.indcrop.2015.08.053

[18] Pizzi, A., Pasch, H., Rode, K. and Giovando, S. (2009) Polymer Structure of Commercial Hydrolysable Tannins by Matrix-Assisted Laser Desorption IonizationTime-of-Light Mass Spectrometry. Journal of Applied Polymer Science, 113, $3847-$ 3859. https://doi.org/10.1002/app.30377

[19] Pan, X., Lachenal, D., Neirinck, V. and Robert, D. (1994) Structure and Reactivity of Spruce Mechanical Pulp Lignins: ${ }^{13} \mathrm{C}-\mathrm{NMR}$ Spectral Studies of Isolated Lignins. Journal of Wood Chemistry and Technology, 14, 483-506. https://doi.org/10.1080/02773819408003109

[20] Catherine, L. and Bernard, M. (1987) $\mathrm{RMN}{ }^{13} \mathrm{C}$ Bidimensionnelle des lignines de peuplier: Etude des Corrélations entre Atomes de Carbone et Réexamen par la Méthode INADEQUATE des Attributions des Signaux du Spectre. Holzforshung, 41, 51-58. https://doi.org/10.1515/hfsg.1987.41.1.51

[21] Wang, K., Xu, F. and Sun, R. (2010) Molecular Characteristics of Kraft-AQ Pulping Lignin Fractionated by Sequential Organic Solvent Extraction. International Journal of Molecular Sciences, 11, 2988-3001. https://doi.org/10.3390/ijms11082988

[22] Tian, X., Fang, Z., Smith Jr., R.L., Wu, Z. and Liu, M. (2016) Properties, Chemical Characteristics and Application of Lignin and Its Derivatives. In: Fang, Z. and Smith Jr., R.L., Eds., Production of Biofuels and Chemicals from Lignin, Springer, Berlin, 3-33. https://doi.org/10.1007/978-981-10-1965-4_1 